\title{
Social media platforms as educational interfaces - considering the way forward for blended learning
}

Kelly Preece, University of Exeter

\begin{abstract}
Despite their pervasiveness, Virtual Learning Environments (VLEs) are subject to a number of criticisms of their efficacy as platforms for blended learning (Weller, 2006). This paper considers the use of social media platform Padlet as an alternative educational interface through evaluation of an intervention-based case-study. Focus groups were conducted with the student cohort, identifying a number of recurring themes that form the main body of this paper: visuality and clarity of the interface, autonomy over learning, students as co-producers and critical reflection. These themes address the intervention itself, and acknowledge the limitations of the research by proposing potential developments. The paper concludes by drawing together questions for further research, and notably reflects on whether it is more pertinent to address the way we use educational interfaces, rather than the interfaces themselves, in considering 'the way forward' for blended learning in Higher Education 2018.
\end{abstract}

Keywords: Blended learning; student experience

\section{Introduction}

In its rudimentary form, Blended Learning involves the use of Information Communication Technologies (ICTs) to support face-to-face teaching. Sharpe et al. observe that the term 'blended learning' is used to refer to three sets of practices; the provision of supplementary resources, use of technology to replace other modes of learning, and teaching and students' own use of technology (2006, p.2). The first is the most common, with resources provided through a traditional and institutionally supported Virtual Learning Environment (VLE). VLE is a term used to refer to an 'online set of tools and spaces that are managed by the institution for use in supporting teaching and learning' (JISC, 2015). These include in-house environments and commercial or proprietary systems such as Blackboard, one of the most prominent VLEs alongside the open-source Moodle (JISC, 2015). Blackboard contains individual learning spaces for each module on which a student is enrolled, with tools to support storage of documents (e.g. lecture slides, reading materials), administration (e.g. enrolment, grading), assessment (e.g. quizzes, electronic submission) and communication (e.g. discussion boards, wikis, blogs) (JISC, 2015).

Martin Weller states that VLEs 'may not be the most innovative educational technology to be found in use today, but they are the most pervasive' (Weller, 2006, p.99). Despite their pervasiveness, numerous criticisms are often railed at both in-house and commercial VLEs. Summarised by Weller, these include that:

- they are content focused 
- they have no strong pedagogy

- they do not meet the needs of different subject areas

(Weller, 2006, p.99)

The content-driven nature of VLEs and lack of pedagogical basis sits uncomfortably with the increasing emphasis in educational theory and research on the active role of the learner in their education (Fry et al., 2008, p.10). As such, there is a need to consider the efficacy of VLEs as tools for blended learning and investigate alternative online spaces where students may play a more active role, and for which there is a strong pedagogical rationale.

Social media technologies have a similar pervasiveness to VLEs, and have been defined by Davis et al. as:

'media used to enable social interaction.... web-based and mobile applications that allow individuals and organizations to create, engage, and share new user-generated or existing content' (Davis et al., 2012, p.1)

Such social media technologies include everything from networking-based technologies such as Facebook, Twitter and Instagram to blogging and content-focused tools such as Tumblr, Pinterest and Padlet. Davis et al. argue that for the current generation of students:

'for whom such social media technology exchanges have existed their entire lives, there is a fluid interchange between digital and physical experiences'. (Davis et al., 2012, p.4)

This 'fluid interchange' is the intention and philosophy of practices of blended learning, and provides an initial rationale for the pedagogical appropriation of social media for blended learning. Considering their extensive usage by students and the suggested propensity to 'create, engage and share', social media platforms might be the way forward for facilitating meaningful blended learning experiences in which students play an active role. This paper reports on a pedagogical intervention that sought to investigate the potential of social media platform Padlet as an alternative online space to the institutionally supported VLE, Blackboard.

\section{Context}

The intervention was conducted on a second year dance history and analysis module at the University of Leeds in the academic year 2012/2013 ${ }^{1}$. The cohort was made up of 9 full-time, female BA (Hons) Dance students. The aim of the module was to introduce students to different methods of researching and experiencing dance to inform their engagement with, and analysis of, historical and contemporary choreographic work. The module was delivered through a weekly four-hour session over the course of a semester, consisting of a one hour lecture or seminar, a one-hour practical workshop, and two hours of studio-based self-directed study. Delivery included a range of teaching and learning modes including lectures, seminars, viewings of dance works, and reconstructions ${ }^{2}$ of extracts of seminal dance works. The module assessment included an essay and a lecture-demonstration.

\section{Students as Digital Natives?}


Having worked closely with the student cohort during the first year of their studies I was acutely aware of their struggle to work as independent learners, particularly in finding their own source materials for assessments. Without heavy tutor assistance on individual assignments they tended to produce work that used only set module readings and internet sources of often questionable quality.

The term digital natives brings with it a range of theoretical baggage and problematic assumptions about the technology - (particularly internet) based behaviours of those born post 1982 (first generation) or after 1990 (second generation) (Helsper \& Enyon, 2010, p.508). However, Helsper and Enyon (2010) argue that the term digital native refers to a way of acting, rather than being a description of a generation. They define these ways of acting as involving multitasking, breadth of use of technologies, using the internet as the first port of call for information, and using the internet for learning (Helsper \& Enyon, 2010, p.506). Rowlands et al. (2008) further this by arguing that although digital natives use the internet as the first port of call for information, they spend little time 'evaluating information, either for relevance, accuracy or authority' that they find online (p.295). Whilst it would be sloppy to define this student cohort as digital natives based on their dates of birth, it is not unreasonable to do so given the information searching and evaluation behaviours they exhibited in the first year of their studies. Therefore the context of digital natives will be discussed, critically, as part of the evaluation of this project. Acknowledging that the discourse of digital natives is largely speculative, this paper uses this literature in the vein of Bullen et al., who argue that such speculative discourse can be used to open up 'new avenues of inquiry' and stimulate 'critical and creative thinking' (2011, p.2-3).

Bullen et al. propose that blending learning design should be based on how students are using technologies, not on generational stereotypes (2011, p.17). Similarly, Bean argues that all pedagogical developments should be student-centred (Bean, 2014). A blended learning intervention on this module needed to address not only the range of teaching and learning modes on the module, but the needs of this student cohort and their technology and internet-based behaviours. As such, my aims were to 1) collate useful online resources as a starting point for independent research 2) bridge the gap between theoretical and practical learning and 3) help students to recognise reliable online source materials.

\section{The Intervention}

In her essay on dance history research methodologies, Berg suggests that a multimedia 'bulletin board' of critical and contextual information would be an enriching accompaniment to reconstruction to support critical learning activities (1999, p.142). Berg's proposal was the impetus for the approach to blended learning explored in this intervention: the creation of multimedia bulletin boards of critical and contextual materials using the social media platform Padlet to support reconstruction workshops. Padlet is a free, online application that purports to be 'the easiest way to create and collaborate in the world' (Padlet, 2015). Previously called Wallwisher, Padlet allows the user to create 'walls' to post and share content with collaborators where a variety of materials can be linked or uploaded, with automatic embedding of content. Linked materials have a 'source' button that takes you out of the wall to the original. Materials can be dragged and dropped around the wall, and all collaborators can add content to the wall or 
rearrange materials. Padlet was chosen as a platform because of the inherent function of the 'walls' as multimedia bulletin boards. The Padlet walls either focused on a particular choreographic work, a choreographer, or a historical period being studied, and included materials such as videos of dance works, interviews with choreographers, critical analyses, photographs, documentaries, reviews, and links to online archives ${ }^{3}$.

The research was outlined to the students as part of the module introduction. The Padlet walls primarily functioned as supporting resources to be accessed at students' discretion, but were introduced as part of a self-directed study task in the first session of the module. The tutor-led part of this session involved a lecture introducing socio-cultural analysis of dance works, and a practical workshop reconstructing an extract of Israeli choreographer Hofesh Shechter's work Political Mother (2010). Following this, students were given self-directed study tasks where they were asked to:

- $\quad$ look at the Padlet wall of materials on Political Mother

- complete a choreographic task

- prepare a short presentation, showing their creative work and discussing their understanding and analysis of the socio-cultural themes in the work.

This task was intended to provide a potential model for student engagement with the Padlet walls as part of their self-directed study and assessment work.

The materials on the Padlet walls were by no means exhaustive but provided a critical basis for engagement - both with our studio work and the wealth of (reliable) online materials about dance/history. The Padlet walls were designed to support the transition between face-to-face contact with the tutor in the studio and critical and contextual appreciation of dance works online.

\section{Evaluation Methodology}

To evaluate the intervention, I conducted a focus group with the student cohort at the end of the module delivery. Students were given the option of whether to participate, and two declined. Focus groups were selected as a data collection method to engage with student's experiences and points of view (Kitzinger, 2005, p.57) on the intervention as the basis for evaluation. The focus group was semi-structured around a range of discussion topics and questions were prepared based on the aims for the intervention. They related to: the interface, the resources posted, access and engagement, relationship to studio learning, wider use of social media educationally and socially, and suggestions for potential developments. These topics provided a basis with the intention to facilitate discussion and debate amongst the students rather than to direct discussion myself (Liamputtong, 2011, p.3). In this way the students had the 'freedom to elaborate on certain topics or move the discussion to areas that the researcher had not foreseen' (Finlayson, 2014, p.51).

The focus groups were audio-recorded with participants' consent ${ }^{4}$ and transcribed verbatim ${ }^{5}$. These transcriptions were then reviewed in detail and coded by identifying emerging themes. In evaluating the intervention these themes not only reflect on the intervention as it was delivered, 
but make suggestions for developments. As such, the discussion part of this paper is split in to two sections, each addressing two themes:

- Reflections on the intervention - visuality and clarity of the interface and autonomy over learning

- Potential Developments - students as co-producers of learning resources and facilitating critical reflection

In considering each of these themes in turn, this paper will foreground student comments as the starting point for discussion - to keep the student voice at the heart of reflection and evaluation alongside contextualisation with relevant pedagogical literature. The section on Potential Developments address the limitations of the research, and makes recommendations for further practice. The conclusion of this paper will draw together questions raised by this discussion about VLEs, social media and 'the way forward' for blended learning.

\section{Discussion: Reflections on the intervention}

\section{'Oh l'll just look at that'}

In response to questions about the presentation and layout of information on the Padlet walls (see Fig. 1 for an example), one of the key points of discussion was the visuality and clarity of Padlet as an interface. Jane commented that 'It looks more interesting. You look at it and think 'Oh I'll just look at that'.

\section{Hofesh Shechter's Political Mother (2010)}

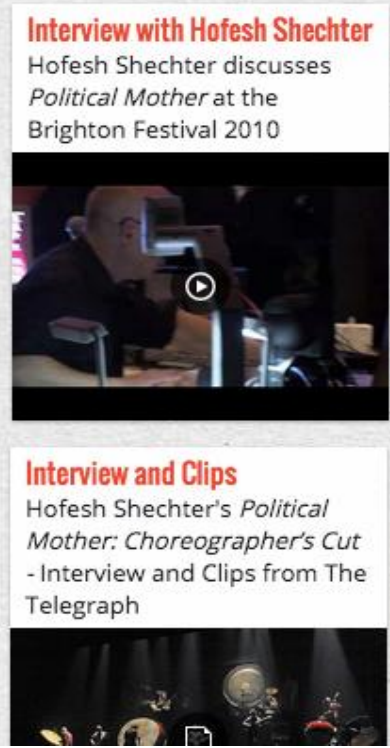

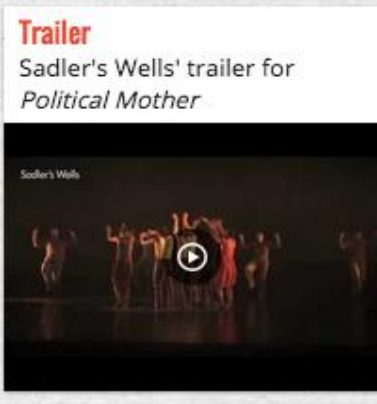

Review

From Luke Jennings in The Guardian

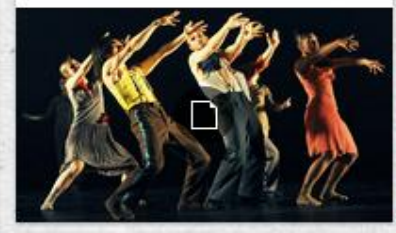

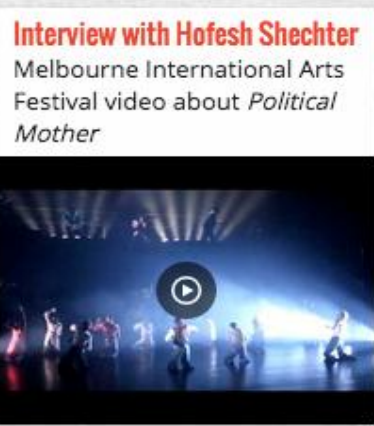

Interview with Hofesh Shechter Article in The Telegraph

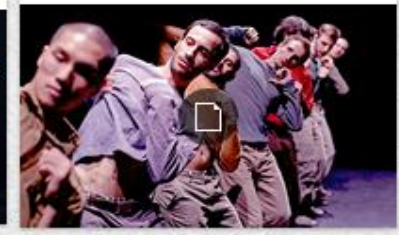

Trailer

Trailer for Political Mother:

The Choreographer's Cut

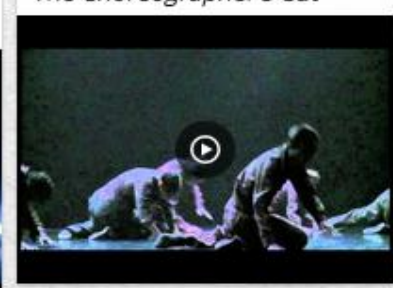

Review

From Jenny Gilbert in The Independent

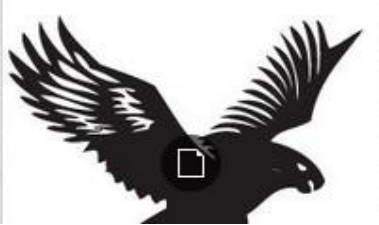

Figure 1: Screenshot of Padlet wall in Hofesh Schether's Political Mother (2010) 
In their work on Personal Learning Environments (PLEs) and interface design, Turker and Zingel echo Jane arguing that 'visuals link easily to intuition and hence urging the user to move, to act' (2008, p.4). Jones et al. cite arguments that so called digital native or 'net generation' students are more oriented to visual media than their predecessors, and that they expect to be engaged by a sensory-rich environment (Jones et al., 2010, p.722). Jones et al.'s work lacks a robust evidence base, but in stating that the Padlet walls 'looked more interesting' and that this corresponded to engagement, these students are demonstrating an orientation towards visual presentation of learning resources. As such, this point is worthy of further consideration. Later discussions revealed that it was not just the visuality of Padlet that corresponded to engagement but the way in which linked resources are embedded in the walls:

'...you can see the structure of different sources, so you can just pick something in between lectures of something you can just go on that and read it and stuff, or look at it, its a lot quicker or easier if you know what I mean,' (Holly).

'If you went on the VLE you don't, when you click on it you don't know if it's going to be a 200 page thing or if it's going to be some pictures, you don't know what it's going to be, ' (Sophie).

Being able to see a snapshot of the content in advance of 'clicking' and (hopefully) engaging, was clearly important to this group of students in comparison to what they termed the 'pot luck' of the VLE.

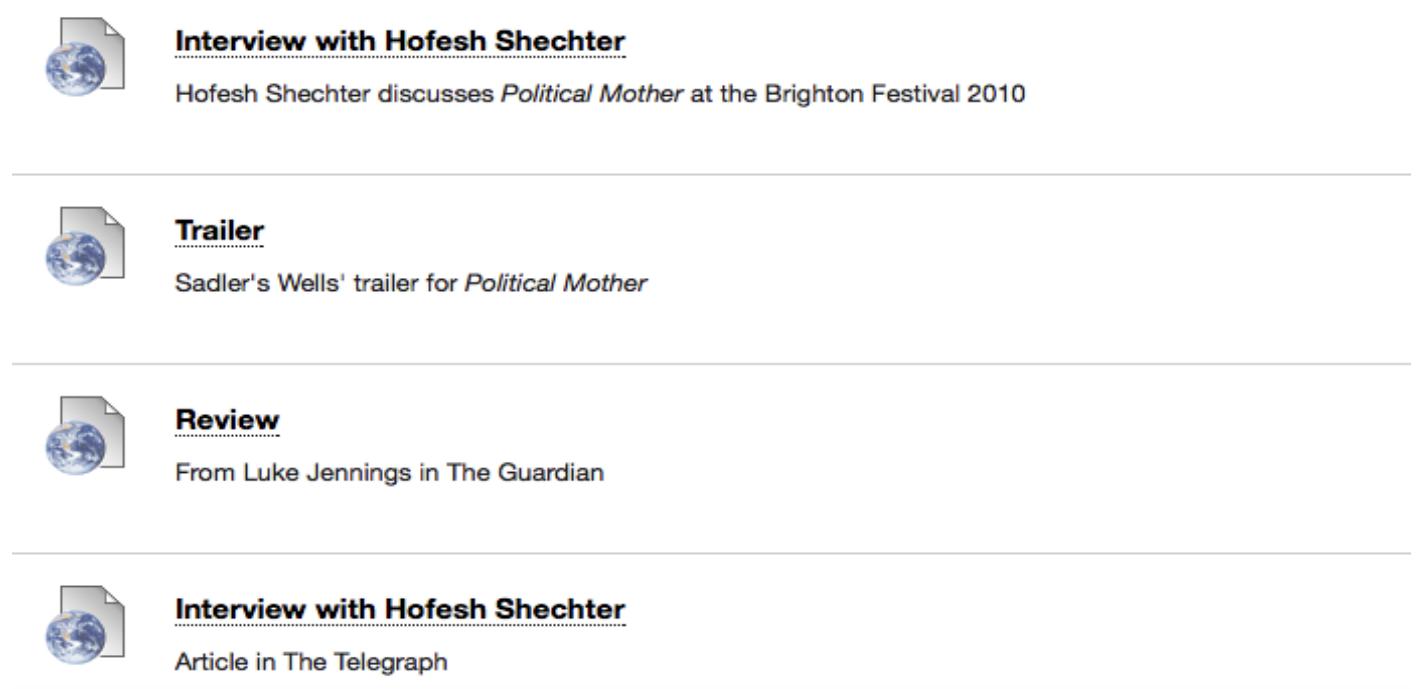

Figure 2: Screenshot of the same resources on Blackboard

For this cohort, the fact that Padlet 'looks more interesting' and the ability to see a snapshot of the content of the resources ignites their interest. Padlet and other social media platforms have distinct advantages over VLEs in terms of visuality of the interface - in the ability to embed content and to not be tied down to a list-based presentation of resources (see Fig. 2 for an example of the same resources being displayed on Blackboard). As such, this presents potential advantages in encouraging engagement with supplementary resources through the 'urge to act'. 


\section{Autonomy over learning}

In addition to introducing the Padlet walls in the first session of the module, I also constructed a task to form part of students' preparation for a taught session. Midway through the module I reconstructed Yvonne Rainer's seminal postmodern dance work Trio A (1966) with the students. As preparation for this session I asked students to review the resources on the Padlet wall for Trio $A$ and select 2 or 3 to look at in detail in advance of class, one of which had to be from an academic journal. The construction of this task parallels the approach of Flipped Learning, where content delivery happens at home allowing class time to deliver application, so students can 'see the material in context' (Freeman et al., 2013, p.63-65) - or in this case, in practice. Theoretical content was delivered via the Padlet walls, and the practical application happened in the studio with the tutor in the form of the reconstruction.

My aim was to give the students a degree of autonomy over their learning, supplementing their reading of analytical materials by engaging with the type of resources they found most useful in preparation for a practical class. Inherent in the task were two choices: the medium that they engaged with (such as video, text, images or audio) and the type of content (such as a dance work, a review, a critical analysis, an interview with a choreographer or an artistic statement). Stinson argues that giving students 'choice, freedom, and a sense of control' motivates them 'to find challenging and meaningful learning experiences' (cited in Leijen, 2008, p.148). Giving the students a degree of choice over which materials to engage with in preparation for class, gave them the opportunity to take responsibility for selecting the resources that would give them the most insight into the work we were going to reconstruct.

The focus group was an opportunity to reflect on this decision making process and to make it a 'meaningful learning experience'. Birkenhead and Stevens define reflection as 'purposefully thinking about experience to gain understanding and change practice' (2002, p.2). Claire stated that:

'...I think we feel we're getting the choice to look at, I mean, obviously we all learn in different ways, and I think giving us a variety of sources to look at, we can pick out which we think we're going to learn the most from, rather than being like read this essay, and I don't really work well with essays, so when I read them only little bits go in, so I can fill in the gaps with other sources'.

In the focus group the students were asked to think about their experiences using the Padlet walls in relation to this task, and Claire articulated an understanding of her learning processes. She identified that she struggles to understand some of the content of essays and that engaging with information in other mediums - videos, images, audio and so on - can enhance her understanding of what she reads. For this student, being given a degree of choice over which preparatory materials to engage with facilitated a meaningful development in the understanding of her own learning, and the opportunity to 'change practice' by identifying a potential learning strategy. The construction of this task facilitated a more active and critical engagement - as is the goal of blended learning (Garrison and Kanuka, 2004, 98). The interface is secondary here to the construction the task, which provides students with choice and 'flips' the approach of content delivery in class, application at home. 


\section{Discussion: Potential Developments}

In the intervention Padlet was largely used as an alternative content dissemination tool to the VLE for supplementary resources. McCulloch outlines the inadequacy of the 'student as consumer' model of the student-university relationship, where:

'the university acts as the provider of products and services, in the form of programmes of study and support for the pursuit of programmes, and the student acts as a consumer of those products and that support,' (McCulloch, 2009, p.171).

This 'student as consumer' model is evident in the content focus of VLEs and my own appropriation of Padlet to provide students with resources (Weller, 2006, p.99). Through this we begin to see the limitations of my intervention. Despite the potential benefits of Padlet's highly visual interface in increasing engagement, the students are not taking a more active role in their learning than they would if this blended learning strategy were delivered using Blackboard. The issue here is not the interface, but the way that I have used it to facilitate blended learning relegating students to a passive rather than active role.

The rest of the discussion part of this paper will propose two developments to the intervention drawn from discussions about student use of social media platforms in their studies and their suggestions. In addition, I will provide a rationale for their adoption and highlight the benefits of social media platforms over VLEs in this regard. As such, they are intended to recognise the limitations of the intervention and make recommendations for my own and others practice.

\section{Students as co-producers}

In the focus groups I asked the students about the ways in which they already use social media platforms in their studies. The primary response was that they used Facebook as a means to communicate as well as share learning resources and useful links. This is often in designated module or programme 'groups' that are set up separate from their social feeds:

'Yeah it's just for, it's basically for communication and say if we found something particularly useful that the rest of the group might benefit from, it's easy just to literally say 'look at this here's the link,' (Claire).

Given the tendency of this cohort to collaborate and share resources on Facebook, it seems prudent to capitalise on this when devising a blended learning strategy. This could be done through providing the opportunity for them to post resources to the Padlet walls alongside the tutor, as there is a strong pedagogical rationale for students becoming co-producers of their learning experiences. In using Blackboard and social media platforms as dissemination tools, students are relegated to being a 'passive receiver' of a service (McCulloch, 2009, p.177). However, McCulloch proposes the model of the 'student as co-producer' which sees students share responsibility with tutors for their learning process through working in partnership (2009, p.176). In this instance, the student becomes an active co-producer of (blended) learning resources. 
In comparing the affordances of Blackboard and Padlet to facilitate this co-production, it is prudent to turn to arguments about the implications of Web 2.0 on learning and teaching. Web 2.0 is a term coined by O'Reilly (2005) to describe 'a new generation of web applications and tools' such as Flickr, MySpace, YouTube and Blogger (Brown, 2010, p.3), and the social media platforms discussed in this paper. Brown argues that Web 2.0 tools have the potential to challenge the dominant position of VLEs such as Blackboard as platforms for e-learning as they 'meet user needs better than institutional VLEs' (2010, p.4, p.6). This is because Web 2.0 tools are open access, allow interoperability (Padlet for instance will embed content from other Web 2.0 tools such as YouTube), are easy to use and allow for individual adoption rather than an institution-wide buy in (Brown, 2010, 6). These tools are:

'changing the web from an essentially "broadcast" environment (where a relatively small number publish material to the rest), to one in which we all participate as publishers,' (Brown, 2010, p.4).

In comparing VLEs with Web 2.0, Brown outlines how VLEs confirm 'traditional power relationships' with their focus on broadcasting content and Web 2.0 tools are designed to be social, collaborative and empower individuals (Brown, 2010, p.6). This comparison is evident when we consider the efficacy of students as co-producers of learning resources using Blackboard and Padlet. Blackboard defaults as a repository for information - of lecture slides, reading materials and so on - and reinforces traditional power relationships between teacher and student (Brown, 2010, p.6). The current version of Blackboard in use at the University of Leeds has optional tools that allow students to contribute content, namely blogs and wikis, which can be set up at staff discretion. However, access is controlled rather than open (Brown, 2010, p.6) and they are markedly separate from content areas populated by staff. In contrast, Padlet's default settings allow all visitors to the wall to add content, with the option for administrators to moderate posts before they are added. It is an inherently social and collaborative environment. As a shared digital space, the sense of partnership would be apparent as the content contributions of tutor and student would not be kept separate.

Despite these arguments, there are issues with students co-producing learning resources. As stated, this cohort in particular struggled with criticality in relation to web resources, and the aforementioned research suggests this lack of criticality is more wide-ranging (Rowlands et al., 2008). Potentially the resources students share could be inaccurate or unreliable. The ability to moderate posts on Padlet goes some way to counter this concern, but begins to reinstitute the traditional power relationships Brown criticised in terms of VLEs. Nonetheless this coproduction is worthy of further research, where developing criticality might form part of the blended learning strategy with students evaluating each other's resources.

\section{Facilitating critical reflection}

In my choreography teaching I have developed a practice of filming studio work and posting the videos on Blackboard so that students can watch their work back and reflect on it as it develops. This student cohort were familiar with this practice and brought it up in the focus group as a potential development of my use of Padlet. Their suggestion was that I could have recorded the 
reconstruction work we did in the studio and posted the video alongside the critical and contextual resources to provide opportunities for reflection:

'So that you can reflect back on your work, obviously you can, when you actually do the practical session you obviously get feedback and whatever, but then if you've got all the right resources the video clips that you've recorded, you can actually look back at yourself and reflect on your learning if that makes sense', (Mia).

Posting a video of the class work alongside supporting resources on Padlet has the potential not only to encourage students to critically reflect on their learning in the studio, but to see this work alongside its critical and artistic context. Arguably the functions of posting videos and commenting could be facilitated through Blackboard - via discussion forums and links to YouTube videos. However, the ability to situate resources visually alongside each other using the bulletin board layout of Padlet has the potential to encourage students to make associations between studio and online, and practical and theoretical learning.

Kirk and Pitches (2013) have developed a model of digital reflection in relation to arts pedagogy that outlines how the level of reflection students engage in mirrors the level of manipulation of digital materials. It traverses through using digital devices to capture creative practice (i.e. video), archive and document creative practice (i.e. uploading to a host such as YouTube or a blog), and finally to digital technologies that allow you to frame or re-frame creative practice in some way (i.e. through discussion, blogging or digital storytelling) (Kirk \& Pitches, 2013, p.226). In the context of developing my existing intervention, this would involve the initial capturing of studio practice through video and documentation by uploading to Padlet. Students could then be set a task to 'look again' at the studio work and comment on it in relation to the resources, thus reframing practice.

However Padlet does not have a commenting function. Although this is a limitation of Padlet as an alternative educational interface, there are other social media platforms that could deliver the pedagogical benefits of Padlet that have inbuilt discussion facilities. I would suggest blogging site Tumblr as an alternative interface, which has the facility for commenting on and discussing posts. Tumblr allows the user to choose between a number of themes which allow for different levels of visuality - for example a user can choose a text based blog roll, or a bulletin board style organisation of posts. Tumblr blogs can be kept by individuals or by groups, and a group blog could enable the positive benefits of Padlet - visuality and clarity of the interface and the ability to co-produce learning resources with students - whilst also facilitating discussion and digital reflection ${ }^{6}$.

\section{Concluding Remarks}

The discussion in this paper has begun to address the limitations of this research, however, there are further limitations that need to be acknowledged. Firstly, the focus groups were conducted by myself, and this has the potential to skew student response and produce unreliable data.

Additionally, the use of visual interfaces such as Padlet and Tumblr is perhaps most conducive to arts-based subjects where resource material are more likely to come in a variety of media (although the increase on online, multimedia materials produced by organisations such as the 
Khan Academy and for Flipped Learning may counteract this). Nonetheless, in the same way that speculative discourse on digital natives can 'open up new avenues of inquiry' and 'serve a valuable role in stimulating critical and creative thinking' (Bullen et al., 2011, p.2), this intervention-based case-study has the potential to stimulate further research and debate on blended learning platforms.

In this vein, each of the key themes discussed in this paper has led me to ask further questions about VLEs, social media and blended learning that could be used as the basis for further research - both by myself and other researchers. These are:

- Does a more visually interesting interface encourage student engagement with resources?

- Is the issue the interface (such as Blackboard), or the way that we construct blended learning?

- Are social media platforms more conducive to students having an active role in their (blended) learning?

- How might social media platform be used to facilitate critical reflection on learning?

Although all of these questions might form an interesting basis for concluding remarks, it is the second that has emerged as a through line in discussions. Despite the visual appeal of social media platforms and their potential to encourage engagement and learner autonomy, discussions in the focus group, and subsequent evaluation were more concerned with how these interfaces are used. As such, I have I begun to question if the issue is the interface (such as Blackboard), or the way that we construct blended learning.

Brown advises caution in the adoption of Web 2.0 tools in learning and teaching, citing the promise of VLEs when first introduced to the market and that 'despite their ubiquitous presence, VLEs are not yet living up to the expectations of their champions' (Brown, 2010, p.3). As this paper has begun to discuss, this could be because of the limitations of the interface. However, it could also be the result of lack of meaningful adoption of VLEs in learning design, as there is an 'absence of evidence that VLEs are being used to do anything differently' (Brown, 2010, p.3). I certainly did not use Padlet to 'do anything differently' in this intervention. Although social media platforms or Web 2.0 technologies such as Padlet and Tumblr present a potential pedagogical benefit, is a focus on interface clouding the issue? Is it more pertinent, in fact, to address the way we use educational interfaces rather than the interfaces themselves in considering the way forward for blended learning?

\section{References}

Bean, M. (2014) 'Keynote'. Keynote Speech presented at the Student Education Conference 3: Engaging Leeds. (3rd. University of Leeds, UK, Jan 10, 2014).

Berg, S. (1999) The Sense of the Past. In Fraleigh, S. and Hanstein, P. (eds) Researching Dance: Evolving Modes of Enquiry. Pittsburgh: University of Pittsbugh Press. 
Birkenhead, J. and Stevens, J. (2002) 'The Performance Reflective Practice Project: Reflection \& Professional Practice'. Paper presented at the Shared Visions Conference. (Brighton, UK, September 1-3, 2002).

Brown, S. (2010) 'From VLEs to learning webs: the implications of Web 2.0 for learning and teaching'. Interactive Learning Environments, 18 (1): 1-10. http://dx.doi.org/10.1080/10494820802158983

Bullen, M., Morgan. T. and Qayyum, A. (2011) 'Digital Learners in Higher Education: Generation is Not the Issue'. Canadian Journal of Learning and Technology, 37 (1): 1-24.

Davis III, C. H. F., Deil-Amen, R., Rios-Aguilar, C. and Sacramento Gonzalez Canche, M. (2012) Social Media in Higher Education: A Literature Review and Research Directions. Report printed by the University of Arizona and Claremont Graduate University.

Finlayson, C. (2014) 'Using focus groups to enhance student voice: a work-in-progress exploration of student learning experiences in large classes'. Enhancing the Learner Experience in Higher Education, 6 (1): 49-54. http://dx.doi.org/10.14234/elehe.v6i1.92

Freeman Herreid, C. and Schiller, N. (2013) 'Case Studies and the Flipped Classroom'. Journal of College Science Teaching, 42 (5): 62-66.

Fry, H., Ketteridge, S. and Marshall, S. (2008) Understanding Student Learning. In Fry, H., Ketteridge, S. and Marshall, S. (eds) A Handbook for Teaching and Learning in Higher Education. London: Routledge.

Garrison, D. and Kaunka, H. (2004) 'Blended learning: Uncovering its transformative potential in higher education'. Internet and Higher Education, 7 (2): 95-105. http://dx.doi.org/10.1016/j.iheduc.2004.02.001

Helsper, E. J. and Enyon, R. (2010) 'Digital natives: where is the evidence?'. British Educational Research Journal, 36 (3): 503-520. http://dx.doi.org/10.1080/01411920902989227

JISC. (2015) Use of VLEs with digital media. Available at:

http://www.jiscdigitalmedia.ac.uk/guide/introduction-to-the-use-of-vles-with-digital-media (accessed 24/3/15).

Jones, C., Ramanau, R., Cross, S. and Healing, G. (2010) 'Net generation or Digital Natives: Is there a distinct new generation entering university?'. Computers \& Education, 54 (3): 722-732. http://dx.doi.org/10.1016/j.compedu.2009.09.022

Kirk, C. and Pitches, J. (2013) 'Digital reflection: using digital technologies to enhance and embed creative processes'. Technology, Pedagogy and Education, 22 (2): 213-230.

http://dx.doi.org/10.1080/1475939X.2013.768390 
Kitzinger, J. (2005) Focus group research: using group dynamics to explore perceptions, experiences and understandings. In Holloway, I. (ed) Qualitative Research in Health Care. Maidenhead: Open University Press.

Liamputtong, P. (2011) Focus Group Methodology London: Sage Publications Ltd.

Leijen, A., Admiraal, W., Wildschut, L. and Simons, R. (2008) 'Students' perspectives on elearning and the use of a virtual learning environment in dance education'. Research in Dance Education, 9 (2): 147-162. http://dx.doi.org/10.1080/14647890802087951

McCulloch, A. (2009) 'The student as co-producer: learning from public administration about the student-university relationship'. Studies in Higher Education, 34 (2): 171-183. http://dx.doi.org/10.1080/03075070802562857

O'Reilly, T. (2005) What is Web 2.0: Design patterns and business models for the next generation of software. Available at: http://www.oreilly.com/pub/a/web2/archive/what-is-web20.html (accessed 25/3/15).

Padlet (2015) Welcome to Padlet. Available at: https://padlet.com (accessed 24/3/15).

Sharpe, R., Benfield, G., Roberts, G and Francis, R. (2006) The undergraduate experience of blended e-learning: a review of UK literature and practice. Available at: https://www.heacademy.ac.uk/resources/detail/teachingandresearch/Undergraduate_Experience (accessed 19/8/15).

Türker, M.A. and Zingel, S. (2008) Formative Interfaces for Scaffolding Self-Regulated Learning in PLEs. elearningpapers. Available at:

http://www.openeducationeuropa.eu/en/article/Formative-Interfaces-for-Scaffolding-Self-

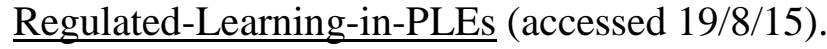

Rowlands, I., Nicholas, D., Williams, P., Huntingdon, P., Fieldhouse, M., Gunter, B., Withey, R., Iamali, H. R., Dobrowolski, T. and Tenpoir, C. (2008) The Google generation: the information behaviour of the researcher of the future. Aslib Proceedings: New Information Perspectives, 60 (4): 290-310. http://dx.doi.org/10.1108/00012530810887953

Weller, M. (2006) VLE 2.0 and future directions in learning environments. Proceedings of the First International LAMS Conference 2006: Designing the Future of Learning Available at: http://lamsfoundation.org/lams2006/pdfs/Weller_Lams06.pdf (accessed 24/3/15).

\section{Notes}

${ }^{1}$ For further context, this was the first year I delivered this module and the last time it ran at this institution as the BA (Hons) Dance at the University of Leeds was phased out from September 2011-August 2014. 
${ }^{2}$ In dance practice and studies, reconstruction refers to the re-staging of historical works and techniques.

${ }^{3}$ The Padlet walls were on Hofesh Shechter (1975-), Martha Graham (1894-1991), Merce Cunningham (1919-2009), Yvonne Rainer's Trio A (1966), 'New Dance' (1970s-1990s), Lea Anderson (1960-), and 'Experimental Dance' Practice in Europe (1990s-), can be accessed via the hyperlinks and are best viewed in Google Chrome.

${ }^{4}$ The project was submitted for and passed ethical approval at the University of Leeds. Consent for participation in the focus group, audio recording and use in published materials was given verbally at the start of the focus group. The students have been anonymised in this paper through the use of pseudonyms.

${ }^{5} \mathrm{Ums}$ and ahs have been removed from the quotations used in this paper for clarity.

${ }^{6}$ This would also deal with formatting issues on Padlet, as the layout of contents shifts between browsers. This does not happen on Tumblr.

\section{About the author}

Kelly Preece is the Researcher Development Programme Manager for Postgraduate Research Students at the University of Exeter. She has previously worked as a Lecturer in Dance at the University of Leeds and the University of Northampton. Her research encompasses the use of technology in dance performance and pedagogy.

Email: k.preece@exeter.ac.uk 